\title{
Dilemmas in management of bilateral ectopic pregnancies-report of two cases and a review of current practice
}

\author{
Arpita Ghosh • Daniel Borlase • Tosin Ajala • \\ Anthony James Kelly $•$ Zaky Ibrahim
}

Received: 28 January 2014 / Accepted: 15 May 2014 /Published online: 4 June 2014

(C) Springer-Verlag Berlin Heidelberg 2014

\begin{abstract}
Simultaneous bilateral ectopic pregnancies occurring spontaneously or following assisted conception techniques, although rare, present the clinician with diagnostic uncertainty and management dilemmas which may have an implication on the patient's future fertility. A review of available literature suggests that there is no universally accepted management strategy towards this condition, and care needs to be tailored to the needs of the patient, patient's preferences and the clinical picture. We report two such rare cases of simultaneous bilateral ectopic pregnancies with different management and outcomes highlighting the fact that these cases not only pose diagnostic and management challenges but also has complex ethical issues associated with it.
\end{abstract}

Keywords Bilateral ectopic $\cdot$ Salpingostomy $\cdot$ Salpingectomy

\section{Introduction}

Simultaneous bilateral ectopic pregnancies occurring spontaneously or following assisted conception techniques are rare, with an incidence reported to be between 1 in 725 to 1 in 1,580 of all extrauterine pregnancies Rondeau et al. [1].

A. Ghosh $(\bowtie) \cdot$ D. Borlase $\cdot$ T. Ajala $\cdot$ A. J. Kelly

Brighton and Sussex University Hospitals NHS Trust, Brighton, UK

e-mail: arpitagmc@yahoo.com

D. Borlase

e-mail: danielborlase@hotmail.com

T. Ajala

e-mail:Tosin.Ajala@bsuh.nhs.uk

A. J. Kelly

e-mail: Tony.kelly@bsuh.nhs.uk

Z. Ibrahim

Western Sussex Hospitals NHS Trust, West Sussex, UK

e-mail: Zaky.Ibrahim@wsht.nhs.uk
Management of these rare cases presents the clinician with diagnostic and management dilemmas. This is primarily due to rarity of the condition posing diagnostic difficulties with ultrasonography and implication of its treatment on fertility of the women.

We report two such rare cases of simultaneous bilateral ectopic pregnancies with different management and outcome, highlighting the fact that these cases not only pose diagnostic and management challenges but also has complex ethical issues associated with it.

\section{Case reports}

Case 1

History

A 37-year-old lady self-referred to the Early Pregnancy Assessment Unit (EPAU) at our local hospital at approximately 6 weeks into a planned pregnancy (Fig. 1). She presented with vaginal spotting which self resolved 7 days before attending. She denied any abdominal pain. Her previous obstetric history was that of a forceps-assisted delivery in 2008 and an early miscarriage in 2012. There was no history of previous tubal problems, gynaecological surgery or pelvic inflammatory disease. Her Abdominal and pelvic examination was unremarkable.

A transvaginal ultrasound scan on the day she presented revealed an empty uterus with an endometrial thickness of $7 \mathrm{~mm}$. The right ovary showed two small haemorrhagic cysts of about the same size $(18 \mathrm{~mm} \times 12 \mathrm{~mm} \times 16 \mathrm{~mm})$. Adjacent to the left ovary was a solid cystic lesion approximately $34 \mathrm{~mm} \times$ $33 \mathrm{~mm} \times 19 \mathrm{~mm}$ in size (Fig. 2). This lesion demonstrated no colour Doppler flow. 


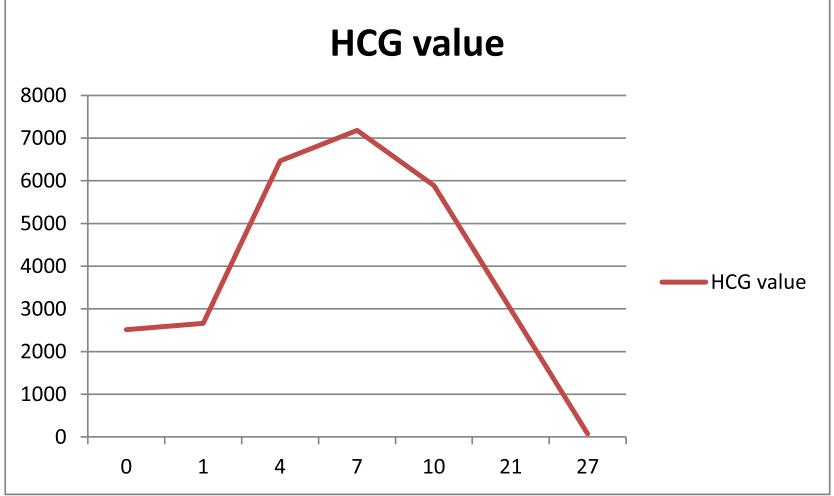

Fig. 1 Trend of HCG level in IU plotted against number of days

In view of her scan findings, particularly the empty uterus, blood was taken for serum levels of $\beta$-human Chorionic Gonadotrophin ( $\beta$-hCG), progesterone and a full blood count. Her $\beta$-hCG was reported to be 2,512 IU with progesterone of 56.3 IU. Her Haemoglobin level was normal.

In view of her $\beta$-hCG level and scan findings, the decision was made to perform a diagnostic laparoscopy with a possibility of proceeding to salpingectomy as an emergency procedure. This was in line with the local guideline according to which laparoscopy is indicated in women with B-hCG more than 1,500 with no evidence of intrauterine gestation.

Laparoscopy revealed a $20-\mathrm{mm}$ swelling in the midampullary region covered with inflammatory material, suggestive of a chronic ectopic pregnancy. On further assessment, a smaller bean-shaped swelling of approximately $10 \mathrm{~mm}$ size in the mid-ampulla of the right tube was noticed (Fig. 3). This had the appearance of an acute tubal ectopic pregnancy. The options at this point were to do bilateral salpingectomy, salpingectomy and salpingostomy salpingectomy and methotrexate management or only methotrexate management. Due to the facts that the patient was asymptomatic, bilateral ectopic

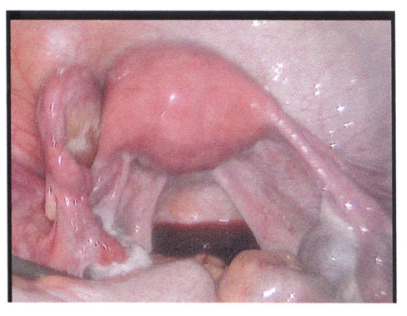

Image_005

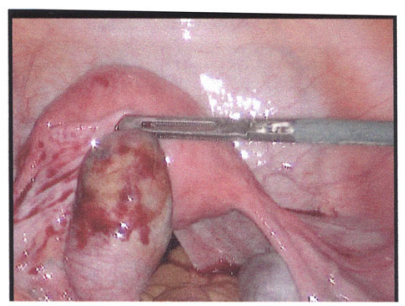

Image_006
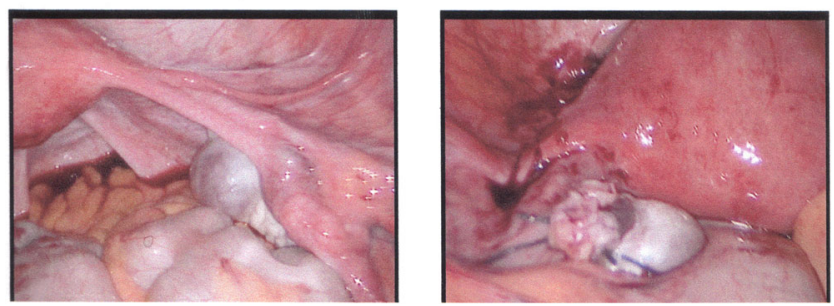

Fig. 2 Pictures showing left chronic tubal ectopic pregnancy case 1 pregnancy was an incidental finding, patient was not consented for further surgery, right tubal pregnancy was less than $3 \mathrm{~cm}$ in size and serum HCG was less than 3,000; the decision was made to perform salpingectomy only on the left side. Further management of right acute unruptured tubal pregnancy was deferred pending discussion with the patient pertaining to implications on her future fertility.

Postoperatively, the findings were explained to the patient, and the options were discussed which included conservative management, medical management with methotrexate and further laparoscopic surgery with a view to do salpingostomy. After a detail discussion, it was decided to manage this patient with methotrexate, which was given the day after her initial surgery. In line with the local protocol, plan was made to monitor her $\beta$-hCG levels on days $1,4,7$ and 10 following methotrexate treatment.

Patient was clinical assessed after it was noted that $\beta$-hCG levels were rising on day 4 (see Fig. 1) after treatment with methotrexate. She was pain free and well. She was then treated with oral mifepristone $200 \mathrm{mg}$ stat and was allowed home pending her further $\beta$-hCG level on day 7 .

On day 7 , her $\beta$-hCG levels were still rising, but she remained asymptomatic. At this point, the option of surgical management was re-discussed, and it was decided to continue to manage her conservatively. By day $10,18 \%$ decline in her HCG levels was noted. The mifepristone was repeated, and she was reviewed again 7 days later. Her $\beta$-hCG was still declining but not at a satisfactory rate. As the patient was still not complaining of any symptoms, it was decided to repeat the methotrexate regime. A steady decline in HCG levels was noted after the second cycle of Methotrexate treatment. The levels dropped down to 72 on day 10 following second cycle of methotrexate.

She was followed up in gynaecology outpatient clinic, and arrangements were made for her to under a go a laparoscopy and dye to test for tubal patency. At laparoscopy, the right tube had an appearance of chronic ectopic but her serum HCG at this point was less than 1. Hydrotubation revealed a free spillage of dye from the right tube confirming its patency.

\section{Case 2}

A 34-year-old woman with a BMI of 26 was referred to the infertility clinic with a 2 -year history of primary infertility. No identifiable risk factors for sub-fertility were present in her and her partner. Her hormone profile did not reveal any abnormality. Hysterosalpingogram revealed bilaterally patent tubes with normal uterus.

Following the cycle of IUI, she presented at 5 weeks of gestation to the early pregnancy clinic with light per-vaginum bleeding and mild left iliac fossa pain. Pelvic ultrasound did not show any intrauterine gestation sac and reported the endometrial thickness of $10 \mathrm{~mm}$ with two small cystic areas 

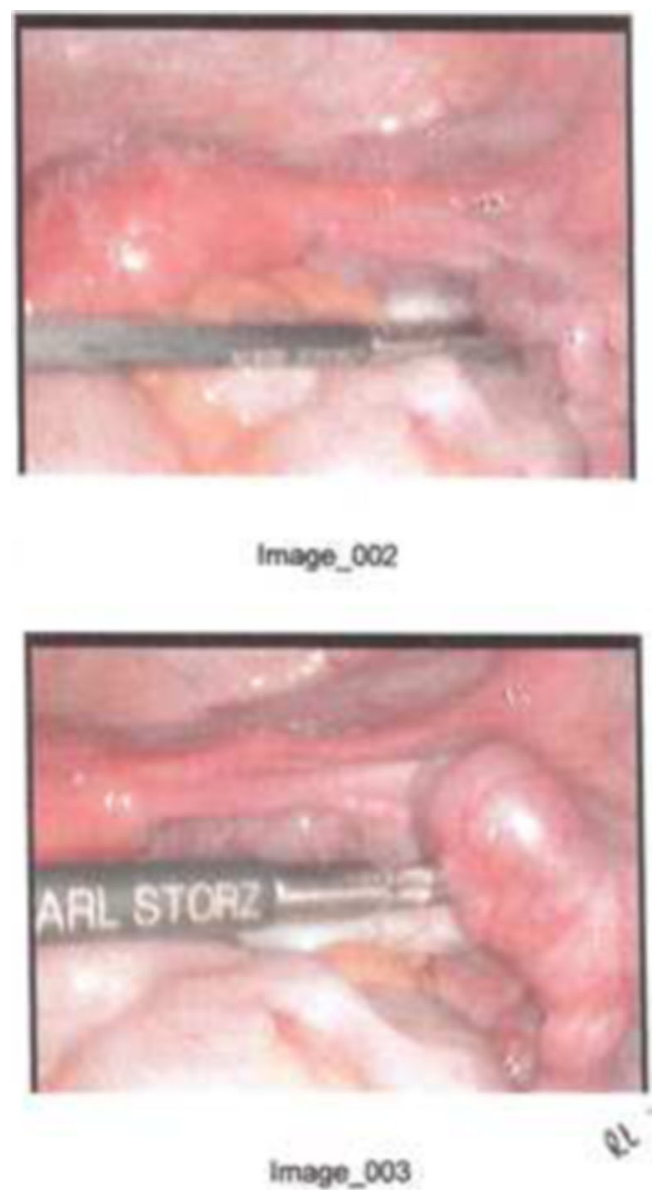

Fig. 3 Pictures showing right acute tubal ectopic pregnancy case 1

near both ovaries suggestive of either a corpus luteal cyst or ectopic pregnancies. Her serum HCG level was 9,691 IU and she was haemodynamically stable. She was admitted to the hospital with a provisional diagnosis of 'pregnancy of unknown location', and the possibility of ectopic pregnancy was explained to her. A diagnostic laparoscopy was planned the following day, and the patient was counselled and consented for a possible salpingectomy.

Laparoscopy revealed bilateral haemorrhagic masses with a small amount of blood in the pouch of Douglas. As the patient was already seeking fertility treatment for unexplained infertility and the option of IVF was available to the couple if IUI treatment failed, the decision was made to perform bilateral salpingectomies and thereafter plan further IVF treatment. Histology confirmed the diagnosis of bilateral ectopic pregnancies. She and her partner were then offered IVF to help attain pregnancy. A year later, she had a successful intrauterine pregnancy following IVF treatment.

\section{Discussion}

Ectopic pregnancy is an important cause of maternal mortality and morbidity. Every 11 in 1,000 pregnancies are reported to be an ectopic (CEMACH report 2003-2005). The latest CEMACH report from 2003-2005 emphasise the importance of early recognition and diagnosis of such pregnancies to save mothers' lives. There has been a persistent failure to recognise ectopic pregnancy and hence one of the 'top ten' key recommendations from the latest CEMACH report is that there should be national guidelines for the management of pain and bleeding in early pregnancy. Comprehensive clinical guidelines for the treatment of ectopic pregnancy have been published by the Royal College of Obstetricians and Gynaecologists. Because of its rarity, bilateral ectopic pregnancy is not referred to in the guidelines, but the same principles of management can still be applied.

The main purpose of reporting these two cases of bilateral ectopic pregnancy is to highlight the two different management approaches for the same condition and to discuss the challenges and dilemmas faced by the clinicians while diagnosing and managing such rare cases. In both the above cases, the noninvasive diagnostic methods with transvaginal ultrasonography and serial serum HCG monitoring failed to establish conclusively the presence of bilateral ectopic pregnancy. Given the rarity of the condition, difficulties in interpretation of serum HCG and the limitations of ultrasonography, timely diagnosis can be difficult. However, its early diagnosis is imperative in preservation of future fertility of the woman.

A review of available literature reveals that in most cases, preoperative investigations with serum HCG and ultrasonography fail to diagnose the presence of bilateral ectopic pregnancy [2]. It is commonly diagnosed intraoperatively at the time of laparoscopy. In the majority of the cases, ultrasonography will diagnose the presence of ectopic pregnancy in one tube, with the subsequent unexpected finding of bilateral ectopics during laparoscopy. This emphasises the importance of maintaining a high index of suspicion and the importance of examining the contralateral tube carefully during the laparoscopy. It can be specially challenging for the clinicians making these complex decisions during an emergency procedure with limited time to discuss and think about the implications of different management options with regards to the women's future chances of conception and the desire for preservation of fertility.

A diagnosis of bilateral tubal ectopic pregnancy at laparoscopy presents the clinician with the dilemma that the curative approach, which is to perform a bilateral salpingectomy, will render the women infertile. Thereafter, the only option of conceiving is through assisted conception technique. This is an important consideration especially as in majority of the cases the condition is found incidentally at laparoscopy giving no time for a detailed discussion with the women regarding its implications. Most of the clinicians choose to attempt conserving at least one tube if not both. In the cases where both tubal ectopic pregnancies are found to be ruptured and patient is haemodynamically compromised, it may be reasonable to 
perform a bilateral salpingectomy as a lifesaving measure. Also, in cases where a woman is already considering an IVF treatment and performing a conservative tubal surgery would increase her risk of further ectopic pregnancy, bilateral salpingectomy can be considered as a treatment of choice provided that this has been discussed with the women. Loo et al. [3] reported the rare occurrence of spontaneous synchronous bilateral ectopic pregnancy in a haemodynamically unstable patient needing bilateral salpingectomy. Martinez J et al. reported one such case where bilateral salpingectomy was performed, and Marasinghe JP et al. reported a case where the patient needed emergency laparotomy in view of ruptured ectopic pregnancy.

However, in majority of the cases, it is either both ectopic pregnancies are unruptured or there is a unilateral ruptured ectopic pregnancy. Stamatellos I.et al. described a case of unrecognised bilateral ampullary ectopic pregnancy, and bilateral salpingostomy was performed for this. Eze $\mathrm{JN}$ et al. reported a case of spontaneous bilateral ectopic pregnancy with one ruptured and one unruptured ectopic pregnancy needing both salpingectomy and salpingostomy.

Conservative management poses further dilemma between performing a salpingostomy and opting for a medical management with methotrexate postoperatively. In haemodynamically stable patients with unruptured tubal pregnancy, systemic methotrexate and laparoscopic salpingostomy are both successful in treating the majority of cases, and there is no significant difference between the treatments in the homolateral patency rate. (Dr PJ Hajenius et al.).

Salpingostomy is a conservative tubal surgery, but it carries the risks of incomplete evacuation and persistence of gestational tissue post procedure. Moreover, salpingostomy is performed less frequently and consequently in the present system of training most of the clinicians are not trained enough to perform this competently, especially so in an emergency situation. This also re-emphasises the importance of pre-empting this rare condition so that the surgery could be as planned as possible with appropriate expertise available. Rammah A.M. reported a case of bilateral unruptured ectopic pregnancy following assisted conception technique, and the women had bilateral salpingostomy performed.

There was one report (Marcovici I.et al.) where methotrexate management was opted for bilateral ectopic pregnancy, but it failed and authors questioned the optimal dose of methotrexate to treat bilateral ectopic pregnancy. Methotrexate management postoperatively needs further monitoring of the patient with serial HCG and the risk of needing further surgery persists. However, it gives the clinician an opportunity to discuss treatment options with the women and have an informed consent to proceed with management decisions. While managing such rare but fatal cases, the clinician should carefully consider and weigh the risks and benefits of each of the treatment option in the light of individual patient's condition.
The incidence of simultaneous bilateral ectopic pregnancies is between 1 in 725 and 1 in 1,580 of all extrauterine pregnancies (Rondeau JA et al.) Although spontaneous bilateral ectopic pregnancies have also been reported, these are rare. The majority of such cases happen as a consequence of assisted conception techniques primarily with IVF. Reddy et al. [2] and Shetty JP et al. report cases of spontaneous bilateral ectopic pregnancy highlighting the diagnostic pitfalls and treatment options. Wali AS et al. also describe a similar case with diagnostic challenges and state that occurrence of bilateral ectopic pregnancies is on increase.

With the advent of artificial reproductive techniques, the risk of ectopic pregnancies has increased in the last few years. The risk of developing unilateral ectopic pregnancy following intrauterine insemination with ovarian stimulation is well recognised and is quoted to be between 4 and $8 \%$ in literature (Azantee et al. [4] and Chang et al. [5]). However, simultaneous bilateral ectopic pregnancies following IUI is rare, and to our knowledge, there are only very few cases reported. Plotti et al. in [6] reported bilateral ovarian pregnancy after IUI. Shiau et al. in [7] reported a case of severe ovarian hyperstimulation syndrome with simultaneous bilateral tubal pregnancy following intrauterine insemination. Burgos San Cristobal D.J et al. and Woo I et al. each reports similar cases after IUI treatment. Khong et al. [8] and Mathew et al. [9] reported such cases after clomiphene ovulation induction.

Majority of bilateral ectopic pregnancies are reported after ART treatments like IVF and ICSI (intra cytoplasmic sperm injection). Bustos Lopez HH et al. reported two such cases and stated that attempts should be made to diagnose these rare conditions preoperatively using available noninvasive methods. Campo s et al. report a case of bilateral ectopic pregnancies after IVF treatment. These were the only two cases where a preoperative diagnosis of bilateral ectopic pregnancy was made based on transvaginal scan report. Sergent $F$ et al., through their case report, have attempted to explain the reasons for an increase in rate of bilateral ectopic pregnancies in recent years and highlights the importance of thorough pelvic examination at the time of laparoscopy to avoid missing such rare condition. Klipstein S et al. and Reyad R.M. et al. report similar cases after IVF and ICSI treatment, respectively.

In summary, once bilateral ectopic pregnancies have been diagnosed, the management options include the following:

(a) Bilateral salpingectomy

(b) Salpingostomy and salpingectomy

(c) Salpingectomy and methotrexate management

(d) Bilateral salpingostomy

(e) Methotrexate management only

Therefore, the management option has chosen needs to be tailored to the needs of the patient, patient's preferences and 
the clinical picture, preferably after a detailed discussion with the patient.

\section{Conclusion}

Bilateral ectopic pregnancies occurring spontaneously or following assisted conception techniques, although rare, present the clinician with diagnostic uncertainty and management dilemmas. Available literature review suggests that most clinicians opt for a more conservative approach with salpingostomy if the ectopic pregnancy is unruptured, whereas the decision to perform bilateral salpingectomy is noted more in cases where patient is haemodynamically compromised with unilateral or bilateral ruptured ectopic pregnancies. Maintaining a high index of suspicion and examination of the contralateral tube carefully during the laparoscopy is imperative, as it can significantly influence management decisions that can have a long-term influence on the patient's fertility.

Conflict of interest Arpita Ghosh, Daniel Borlase, Tosin Ajala, Anthony James Kelly and Zaky Ibrahim declare that they have no conflict of interest.

Informed consent taken from both patients discussed above This article does not contain any studies with human or animal subjects performed by the any of the authors.

\section{References}

1. Rondeau JA, Hibbert ML, Nelson KM (1997). Combined tubal and cornual pregnancy in a patient without risk factors. A case report. J Reprod Med 42(10):675-677

2. Reddy AP, Chowdhary S, Saxena RK, Venkatesh S, Pandey P (2012) Spontaneous bilateral ectopic pregnancy. BJOG: Int J Obstet Gynaecol 119(151):1470-0328

3. Loo CY, Ng S, Rouse AM (2012) Spontaneous synchronous bilateral tubal ectopic pregnancy: a tale of caution. BJOG: Int J Obstet Gynaecol 119:217-218, 1470-0328

4. Azantee YW, Murad ZA, Roszaman R, Hayati MY, Norsina MA (2011) Associated factors affecting the successful pregnancy rate of intrauterine insemination at International Islamic University Malaysia (IIUM) Fertility Centre. Med J Malaysia 66(3):195-198

5. Chang MY, Huang HY, Lee CL, Lai YM, Chang SY, Soong YK (1993) Treatment of infertility using controlled ovarian hyperstimulation with intrauterine insemination: the experience of 343 cases. J Formos Med Assoc 92(4):341-348

6. Plotti F, Di Giovanni A, Oliva C, Battaglia F, Plotti G (2008) Bilateral ovarian pregnancy after intrauterine insemination and controlled ovarian stimulation. Fertil Steril 90(5):2015.e3-5

7. Shiau CS, Chang MY, Chiang CH, Hsieh CC, Hsieh TT (2004) Severe ovarian hyperstimulation syndrome coexisting with a bilateral ectopic pregnancy. Chang Gung Med J 27(2):143-147

8. Khong SY, Dimitry ED (2005) Bilateral tubal ectopic pregnancy after clomiphene induction. J Obstet Gynaecol 25(6):611-612

9. Mathew M, Saquib S, Krolikowski A (2004) Simultaneous bilateral tubal pregnancy after ovulation induction with clomiphene citrate. Saudi Med J 25(12):2058-2059

\section{Further Reading}

10. Aziz S, Al Wafi B, Al Swadi H (2011) Frequency of ectopic pregnancy in a medical centre, Kingdom of Saudi Arabia. J Pak Med Assoc 61(3):221-224

11. Martínez-Varea A, Hidalgo-Mora JJ, Payá V, Morcillo I, Martín E, Pellicer A (2011) Retroperitoneal ectopic pregnancy after intrauterine insemination. Fertil Steril 95(7):2433.e1-3

12. Bugatto F, Quintero-Prado R, Kirk-Grohar J, Melero-Jiménez V, Hervías-Vivancos B, Bartha JL (2010) Heterotopic triplets: tubal ectopic and twin intrauterine pregnancy. A review of obstetric outcomes with a case report. Arch Gynecol Obstet 282(6):601-606

13. Svirsky R, Maymon R, Vaknin Z, Mendlovic S, Weissman A, Halperin R, Herman A, Pansky M (2010) Twin tubal pregnancy: a rising complication? Fertil Steril 94(5):1910.e13-6

14. Ibrahim AG, Badawi F, Tahlak M (2009) Heterotopic pregnancy: a growing diagnostic challenge. BMJ Case Rep

15. Zadehmodarres S, Oladi B, Saeedi S, Jahed F, Ashraf H (2009) Intrauterine insemination with husband semen: an evaluation of pregnancy rate and factors affecting outcome. J Assist Reprod Genet 26(1):7-11

16. Childs AJ, Royek AB, Leigh TB, Gallup PG (2005) Triplet heterotopic pregnancy after gonadotropin stimulation and intrauterine insemination diagnosed at laparoscopy: a case report. South Med J 98(8):833-835

17. Chueh HY, Cheng PJ, Wang CW, Soong YK (2002) Inadvertent superovulation and intrauterine insemination during pregnancy: a lesson from an ectopic gestation. J Assist Reprod Genet 19(2):87-89

18. Berliner I, Mesbah M, Zalud I, Maulik D (1998) Report of a case with successful twin intrauterine gestation. J Reprod Med 43(3):237-239

19. Bontis J, Grimbizis G, Tarlatzis BC, Miliaras D, Bili H (1997) Intrafollicular ovarian pregnancy after ovulation induction/ intrauterine insemination: pathophysiological aspects and diagnostic problems. Hum Reprod 12(2):376-378

20. Kably Ambe A, Garza Rios P, Serviere Zaragoza C, Delgado Urdapilleta J (1992) [Heterotopic pregnancy in intrauterine insemination. Presentation of a case]. [Article in Spanish]. Ginecol Obstet Mex 60:110-111

21. Marcovici I, Scoccia B (1997) Spontaneous bilateral tubal ectopic pregnancy and failed methotrexate therapy: a case report. Am J Obstet Gynecol 177/6(1545-1546):0002-9378

22. Bustos Lopez HH, Rojas-Poceros G, Barron Vallejo J, Cintora Zamudio S, Kably Ambe A, Valle RF (1998) Conservative laparoscopic treatment of bilateral ectopic pregnancy. 2 case reports and review of the literature. [Spanish] Tratamiento laparoscopico conservador del embarazo ectopico bilateral. Informe de dos casos y revision de la literatura. Ginecol Obstet Mex 66(13-7):0300-9041, 0300-9041

23. Klipstein S, Oskowitz SP (2000) Bilateral ectopic pregnancy after transfer of two embryos. Fertil Steril 74/5(887-8):0015-0282, 0015-0282

24. Reyad RM, Aboulghar MA, Serour GI, Mansour RT, Amin YM, Momtaz M, Youssry I (1998) Bilateral ectopic pregnancy with an intact intrauterine pregnancy following an ICSI procedure. Middle East Fertil Soc J 3/1:1110-5690

25. Sergent F, Verspyck E, Marpeau L (2003) Management of ectopic pregnancies complicating in vitro fertilization: a remarkable case of bilateral ectopic pregnancy with independent courses of the pregnancies. [French] Prise en charge des grossesses extra-uterines apres fecondation in vitro: a propos d'un cas remarquable d'une grossesse extra-uterine bilaterale dont chacune des grossesses a evolue independamment. J Gynecol Obstet Biol Reprod 32/3 Pt 1(256-60):0368-2315, 0150-9918

26. Stamatellos I, Anagnostou E, Stamatopoulos P, Bontis I (2006) Unrecognized spontaneous bilateral ampullary pregnancy treated by laparoscopy. Gynecol Surg 3/3(218-219):16132076, 1613-2084 
27. Burgos San Cristobal DJ, Agirregoikoa JA, Albisu M, Mieza J, Corcostegui B, Prieto B, Ramon O, Matorras R (2004) Simultaneous bilateral ectopic pregnancy after IUI [Spanish] Embarazo ectopico bilateral simultaneo tras IAC. Rev Iberoam Fertilidad Reproduccion Humana 21/5(349-353):1132-0249

28. Altinkaya SO, Ozat M, Pektas MK, Gungor T, Mollamahmutoglu L (2008) Simultaneous bilateral tubal pregnancy after in vitro fertilization and embryo transfer. Taiwan J Obstet Gynecol 47/3(338-40): $1028-4559,1875-6263$

29. Issat T, Grzybowski W, Jakimiuk AJ (2009) Bilateral ectopic tubal pregnancy, following in vitro fertilisation (IVF). Folia Histochem Cytobiol 47/5(S147-8):0239-8508, 1897-5631

30. Marasinghe JP, Condous G, Amarasinghe WI (2009) Spontaneous bilateral tubal ectopic pregnancy. Ceylon Med J 54/1(21-2):00090875, 0009-0875

31. Martinez J, Cabistany AC, Gonzalez M, Gil O, Farrer M, Romero JA (2009) Bilateral simultaneous ectopic pregnancy. South Med J 102/ 10(1055-7):0038-4348, 1541-8243

32. Shetty JP, Shetty B, Makkanavar JH, Chandrika (2011) A rare case of bilateral tubal pregnancy. J Indian Med Assoc 109/7(506-7):00195847, 0019-5847
33. Wali AS, Khan RS, Jcpsp NO (2012) Spontaneous bilateral tubal pregnancy. J Coll Physicians Surg Pak 22/2(118-9):1022-386X, $1681-7168$

34. Woo I, Christianson M, Swelstad B, Yates M, Garcia J (2012) Bilateral ovarian ectopic pregnancies following intrauterine insemination after unsuccessful oocyte retrieval. Fertil Steril 97/3 SUPPL. 1(S31), 0015-0282

35. Rammah AM, Al Hijji JY, Amen AM, Chibber R, Ali SA (2012) Bilateral tubal ectopic pregnancy case presentation and review of literature. Int J Gynecol Obstet 119(S707-S708):0020-7292

36. Eze JN, Obuna JA, Ejikeme BN (2012) Bilateral tubal ectopic pregnancies: a report of two cases. Ann Afr Med 11/2(112-5): 0975-5764, 0975-5764

37. Hajenius PJ, Engelsbel S, Mol BWJ, van der Veen F, Ankum WM, Bossuyt PMM, Hemrika DJ, Lammes FB (1997) Randomised trial of systemic methotrexate versus laparoscopic salpingostomy in tubal pregnancy. Lancet 350(9080):774-779. doi:10.1016/S0140-6736(97)05487-1

38. Gazvani MR, Baruah DN, Alfirevic Z, Emery SJ (1998) Mifepristone in combination with methotrexate for the medical treatment of tubal pregnancy: a randomized, controlled trial. Hum Reprod 13(7):19871990. doi:10.1093/humrep/13.7.1987 